\title{
Option of operating speed for vessels under low-carbon economy
}

\author{
Gang $\mathrm{Li}^{1,2}$, Huan $\mathrm{Xu}^{1}$, and Wei Liu ${ }^{1}$ \\ ${ }^{1}$ Shanghai Maritime University, College of Transport And Communications, Shanghai, ${ }^{2}$ W uhan University of \\ Technology, Wuban (China) \\ lililigangganggang@gmail.com,Llovely_xubuan@163.com,weiliu@,shmtu.edu.cn
}

Received: October 2012

Accepted: February 2013

\section{Abstract:}

Purpose: To find out ships' optimum operating speed under low-carbon economy.

Approach: First, it analyzes the relations between ship's carbon emission and the operating speed, gets the optimum speed under which the entire fleet emit minimum carbon, then establishes the relations between the ship owner's profit and the speed, extracts the speed under which the ship owner can gain the maximum profit and founds out it's different from the speed under which the entire fleet emit minimum carbon.

Findings: The government must take effective measures to make the ship owner slowdown and reduce emission.

Originality: It first works out a balance point between the decrease of carbon emission brought by a lower operating speed and the increase of that caused by more vessels putting into service in a mathematical method.

Keywords: Shipping industry; Low carbon emission, Vessel speed, Shipowner's profit

\section{Introduction}

In these years, the rapid increase of greenhouse gases in the air leads to the global climate change mainly appears in a rising temperature, which directly influence human's life and development. According to the report released by IMO, the entire seaborne industry released 1.04 billion tons of $\mathrm{CO}_{2}$ in 2007 , accounting for $3.3 \%$ of the total quantity for global $\mathrm{CO}_{2}$ emission, and 870 million carbon released by international shipment, which accounts for $2.7 \%$ of the total 
(Buhaug et al., 2009). The report forecasts that with the development of seaborne trade, the greenhouse gas emitted by vessels will increase by $150 \%$ 250\% in 2050 compared with that in 2007 if no measure is undertaken (Buhaug et al., 2009).

Many scholars have studied the $\mathrm{CO}_{2}$ emission in shipping industry, for example, Zhang, Zhang and $\mathrm{Li}$ (2008) mentioned that "a $4 \%$ reduction in operating speed will lead to a $13 \%$ reduction in GHG emission for vessels". International Maritime Organization (IMO) proposes three aspects of measures, technology, operation and market mechanism, in the discussion on measures to reduce GHG emission of vessels, which operation aspect contains slowing down the speed, weather alignment, JIT logistic management, efficiently loading and discharging, hull maintenance etc (Psaraftis \& Kontovas, 2010). Corbett, Wang and Winebrake (2009) analyze the cost-effective on slowing down operating speed in the emission reduction seaborne industry.

As known to all, operating speed is a sensitive problem between carrier and shipper, vessels should sail in a competitive speed to win a proper share of the market. Low-speed navigation will bring some chain reactions. In one hand, lower speed will lead to longer voyage time, and then ship owner has to put more vessels to carry the same quantity of cargo and same service frequency. In the other hand, in some conditions, shipper may choose another mode of transportation instead of shipping after comparing the cost and profit. Both two aspects make it difficult to reduce carbon emissions. Therefore, we need to search for a balance between low-carbon emission under low operating speed and high-carbon emission caused by more vessels.

\section{Relation among Operating Speed, Host Power and Oil Consumption, and $\mathrm{CO} 2$ Emission}

\subsection{Relation among Operating Speed, Host Power and Oil consumption}

Vessel host power is divided into indicated power and effective power. There're some relations among ship displacement, host power and operating speed (Zhao, 2006).

$$
N_{e}=\frac{D^{\frac{2}{3}} \cdot V^{3}}{C}
$$

D means ship displacement $(t), V$ means vessel operating speed $(k n), N_{e}$ means vessel host power $(\mathrm{kw}), \mathrm{C}$ is admiralty coefficient.

From this equation we can see, vessel host power is proportional to the cube of the speed, which means a tiny alteration on speed will have an obvious influence on host power. The operational states of the vessel decide the operating speed, as well as oil consumption. 
As the relation between speed and power mentioned above, we can see there're some quantitative relations between operating speed and oil consumption for vessels.

Because a vessel has constant shape, size, and displacement no matter what speed it sails. We can achieve equation (2) from equation (1).

$$
\frac{V_{0}^{3}}{N_{e 0}^{3}}=\frac{V^{3}}{N_{e}^{3}}
$$

$\mathrm{V}_{0}$ means vessel's design speed, $\mathrm{N}_{\mathrm{e} 0}$ means the host power of a vessel under the design speed, $\mathrm{V}$ means vessel's operating speed, $\mathrm{N}_{\mathrm{e}}$ means the host power under speed $\mathrm{V}$.

According to equation (2), after changing speed, or say, under speed $\mathrm{V}$, the host power is,

$$
N_{e}=N_{e 0}\left(\frac{V}{V_{0}}\right)^{3}
$$

G stands for the daily oil consumption of the vessel main engine, it is proportional to the host power of the vessel $\mathrm{N}_{\mathrm{e}}$

$$
G=g_{e} \times N_{e} \times 24 \times 10^{3}=g_{e} \times N_{e 0} \times\left(\frac{V}{V_{0}}\right)^{3} \times 24 \times 10^{3}=G_{0} \times\left(\frac{V}{V_{0}}\right)^{3}
$$

$\mathrm{G}_{0}$ means the daily oil consumption of the vessel's main engine under speed $V_{0}(\mathrm{~kg}), \mathrm{g}_{\mathrm{e}}$ means the oil consumption ratio of the vessel's main engine $(\mathrm{g} / \mathrm{kw} \cdot \mathrm{h})$.

In fact, it has a much more complicated relation between speed and oil consumption, we can come to a conclusion via reference theories, oil consumption is proportional to the square or cube of operating speed.

\subsection{Relation between Vessel Operating Speed and $\mathrm{CO} 2$ Emission}

As known to all, seaborne fuel is carbon compounds. When derv burns, nearly all carbon turn into $\mathrm{CO}_{2}$.So, we can calculate the amount of $\mathrm{CO}_{2}$ with fuel consumption.

The total fuel consumption per vessel per voyage equals to the sum of fuel consumed by both main engine and auxiliary engine, so the equation represents the fuel consumption per vessel per round voyage is as follows.

$$
F_{i j k}=M F_{k} \cdot\left(\frac{V}{V_{0}}\right)^{3} \cdot \frac{2 d_{i j}}{24 V}+\left(A F_{k 1} \cdot \frac{2 d_{i j}}{24 V}+A F_{k 2} \cdot t_{s}\right)
$$

$\mathrm{MF}_{\mathrm{k}}$ means the daily fuel consumption of vessel $\mathrm{k}^{\prime} \mathrm{s}$ main engine under the design speed of $\mathrm{V}_{0}, \mathrm{AF}_{\mathrm{k} 1}$ means the daily derv consumption of vessel k's auxiliary engine per voyage day, $A_{k 2}$ means the 
daily derv consumption of vessel k's auxiliary engine per anchor day, $i, j$ means port of departure and destination respectively. $d_{i j}$ means the distance of this voyage, $t_{s}$ means the layover time in voyage.

Once the oil consumption per vessel per voyage is worked out, we can multiply it with the ratio of carbon content, which is defined as $86.4 \%$, and $\mathrm{CO}_{2}$ conversion rate $(44 / 12)$ (Cariou, 2011). to calculate $\mathrm{CO}_{2}$ emission per vessel per voyage.

$$
C O_{2}=0.8645 \cdot \frac{44}{12} \cdot \sum_{i, j, k} F_{i j k}=3.17 \cdot \sum_{i, j, k} F_{i j k}
$$

Combined with equation (5), we have equation (7) below.

$$
C O_{2}=3.17 \cdot \sum_{i, j, k}\left[M F_{k} \cdot\left(\frac{V}{V_{0}}\right)^{3} \cdot \frac{2 d_{i j}}{24 V}+\left(A F_{k 1} \cdot \frac{2 d_{i j}}{24 V}+A F_{k 2} \cdot t_{s}\right)\right]
$$

\section{Option of Operating Speed for Vessels to Minimize the Carbon Emission and when Considering Ship Owners Profit}

\subsection{Option of Operating Speed for Vessels to Minimize the Carbon Emission}

The decrease of speed means the fewer cargo it transports in the same period of time, and that'll lead to two situations to maintain in a certain service frequency, one is a vessel has to load more cargo by increasing its loading capacity or using more efficient loading technology and packaging system to fulfill the transportation demand, another is putting more vessels in the line to fulfill the continuing transportation demand instead of changing the sailing schedule. But the more vessels putting in this field will lead to the more $\mathrm{CO}_{2}$ emission, which will neutralize the benefit of slowing down the operating speed.

In a short time, it is difficult to achieve the first situation, so currently we only consider the second one. In the precondition of a constant service frequency, we build a speed selection model aiming to minimize the $\mathrm{CO}_{2}$ emission, which searching for a balance point between the decrease of carbon emission per vessel caused by slowing down the operating speed and the increase of carbon emission caused by the more vessels being put into service. Let's take an example.

Supposing there're $n$ vessels in a particular line, dispatch interval is represented by $t_{i}, t_{r}$ stands for the round voyage time which depends on the time for a round voyage and the loading and unloading time at two terminal ports.

$$
t_{r}=\frac{2 d_{i j}}{24 V}+t_{S}
$$


As we have mentioned the meaning of $d i j, v, t_{s}$, the vessel number in a line, $n$ can be represented by the equation below.

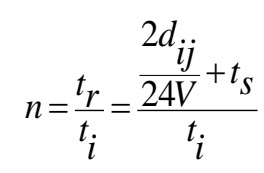

It can be seen that if we keep the dispatch interval unchanged, the vessel number will go up when the operating speed goes down.

As is shown above, $\mathrm{CO}_{2}$ emission per vessel per day is as follows.

$$
Q_{0}=3.17 \cdot \frac{M F_{k} \cdot\left(\frac{V}{V_{0}}\right)^{3} \cdot \frac{2 d_{i j}}{24 V}+\left(A F_{k 1} \cdot \frac{2 d_{i j}}{24 V}+A F_{k 2} \cdot t_{s}\right)}{t_{r}}
$$

So the daily $\mathrm{CO}_{2}$ emission of $\mathrm{n}$ vessels per day is,

$$
Q_{n}=3.17 \times \frac{M F_{k} \cdot\left(\frac{V}{V_{0}}\right)^{3} \cdot \frac{2 d_{i j}}{24 V}+\left(A F_{k 1} \cdot \frac{2 d_{i j}}{24 V}+A F_{k 2} \cdot t_{s}\right)}{t_{r}} \times \frac{t_{r}}{t_{i}}
$$

It's obvious that if the dispatch interval stays unchangeable, $Q_{n}$ is a function of speed V. simplified as,

$$
Q_{n}=\frac{3.17}{t_{i}} \times\left[M F_{k} \cdot\left(\frac{V}{V_{0}}\right)^{3} \cdot \frac{2 d_{i j}}{24 V}+\left(A F_{k 1} \cdot \frac{2 d_{i j}}{24 V}+A F_{k 2} \cdot t_{s}\right)\right]
$$

The derivative of speed $\mathrm{V}$ is as follows,

$$
\begin{aligned}
& \frac{d Q_{n}}{d v}=\frac{3.17}{t_{i}} \times\left(\frac{2 M F_{k} \times V \times d_{i j}}{12 V_{0}^{3}}-\frac{A F_{k 1} \times d_{i j}}{12 V^{2}}\right) \\
& \text { If } \frac{d Q_{n}}{d v}=0 \quad \text { so, } V_{C O_{2}}=\sqrt[3]{\frac{A F_{k 1}}{2 M F_{k}}} \times V_{0} .
\end{aligned}
$$

We can see the operating speed of the fleet that emit the least $\mathrm{CO}_{2}$ depends on the rated oil consumption of both main and auxiliary engines as well as design speed for the vessel.

However, the option of operating speed for vessels is also restrained by technology, so, the option of operating speed is limited, the upper limit cannot surpass the highest speed set by the rated power of the main engine, and the lower limit cannot below the speed main engine's minimum steady speed. From equation (1), the lower limit of the operating speed $\left(V_{S}\right)$ is $67 \%$ of the design speed. If $\mathrm{V}_{\mathrm{CO}_{2}}>\mathrm{V}_{\mathrm{s}}, \mathrm{V}_{\mathrm{CO}_{2}}$ should be chosen as the operating speed, if $\mathrm{V}_{\mathrm{CO}_{2}}<\mathrm{V}_{\mathrm{s}}$, we should take some technical measures. 


\subsection{Option of Operating Speed for Vessels when Considering Ship Owners Profit}

To shipping managers, slowing down the operating speed will cut down the oil cost, which is the major part of the shipping cost, but in order to sustain the service frequency, operating cost of a fleet will increase. Ship owners will always choose an operating speed to minimize the cost and maximize the profit.

Supposing $\mathrm{K}_{\mathrm{s}}$ is a vessel's daily constant cost, including capital cost, operating cost and voyage cost which excludes oil cost (in liner, if quantity of cargo don't change, these costs all could be regarded as constant costs). The daily oil cost for a vessel is represented by $\mathrm{K}_{\text {oil, }}$ so

$$
K_{o i l}=\frac{C_{f} \times M F_{k} \times\left(\frac{V}{V_{0}}\right)^{3} \times \frac{2 d_{i j}}{24 V}+C_{d} \times\left(A F_{k 1} \times \frac{2 d_{i j}}{24 V}+A F_{k 2} \times t_{s}\right)}{t_{r}}
$$

$C_{f}, C_{d}$ mean the price of fuel and derv respectively, Yuan/kg, other letters are the same as above.

As to the same voyage, the vessel number is represented by $\mathrm{n}$. If these ships have the same size, scale, capital and operating cost, the daily total cost of these $n$ ships is,

$$
C=\left\{K_{s}+\frac{C_{f} \times M F_{k} \times\left(\frac{V}{V_{0}}\right)^{3} \times \frac{2 d_{i j}}{24 V}+C_{d} \times\left(A F_{k 1} \times \frac{2 d_{i j}}{24 V}+A F_{k 2} \times t_{S}\right)}{t_{r}}\right\} \times \frac{t_{r}}{t_{i}}
$$

Simplified as follows,

$$
C=\frac{1}{t_{i}} \times\left[k_{s} \times\left(\frac{2 d_{i j}}{24 V}+t_{s}\right)+C_{f} \times M F_{k} \cdot\left(\frac{V}{V_{0}}\right)^{3} \cdot \frac{2 d_{i j}}{24 V}+C_{d} \times\left(A F_{k 1} \cdot \frac{2 d_{i j}}{24 V}+A F_{k 2} \cdot t_{s}\right)\right]
$$

So, total cost $C$ is the function of speed $V$, the derivative of $V$ is,

$$
\begin{gathered}
\frac{d C}{d V}=\frac{1}{t_{i}} \times\left[-\frac{k_{s} d_{i j}}{12 V^{2}}+\frac{2 C_{f} \times M F_{k} \times V \times d_{i j}}{12 V_{0}^{3}}-\frac{C_{d} \times A F_{k 1} \times d_{i j}}{12 V^{2}}\right] \\
\text { If } \frac{d C}{d V}=0 \quad \text { so, } V_{c}=\sqrt[3]{\frac{C_{d} \times A F_{k 1}+k_{s}}{2 C_{f} \times M F_{k}}} \times V_{0}
\end{gathered}
$$

We can come to a conclusion that the maximum operating speed relates not only to the daily rated oil consumption of both main and auxiliary engines as well as design speed, but to the prices of fuel and derv, and vessel's daily constant cost. 
The model above doesn't consider the influence of competence for a fleet with the lower operating speed, which affect the cargo capacity of vessel, freight income and profit of ship operators. So we should do some modifications to the model above. We use $K_{r}$ to represent the average daily loss of opportunity cost because of slow steaming, and add it to the formula (13) to calculate the derivative of speed $\mathrm{V}$, after modification, the maximum speed for a profitable vessel is:

$$
V_{c}^{\prime}=\sqrt[3]{\frac{C_{d} \times A F_{k 1}+k_{s}+k_{r}}{2 C_{f} \times M F_{k}}} \times V_{0}
$$

\section{The participation of government in the aspect of operating speed}

Generally, the price of derv used by auxiliary engine is higher than that of fuel used by main

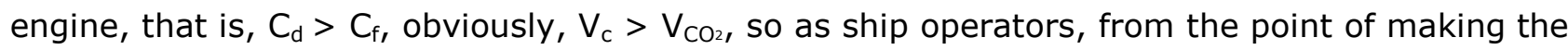
most profit or paying the least cost for the company, they will always order the fleet sails faster than the speed that emit the least $\mathrm{CO}_{2}$. It's obviously not good for the environment, so government needs to take measure to manage and control it. Common measures are economic methods such as collecting fuel tax and carbon tax(research shows that, collecting fuel tax at $40 \%$ the worth of oil price could cut down $10 \%$ 20\% of carbon emission for vessels), or compulsory means such as setting a restricted speed for vessel.

\section{Conclusion}

Currently, slowing down the operating speed is an effective way to sharply decrease the quantity of carbon emission in a short time. This article find a balance point between the decrease of carbon emission brought by a lower operating speed and the increase of that caused by more vessels putting into service in a mathematical method. This article works out the operating speed when maximizing ship owner's profit, and it finds out the speed when the fleet's carbon emission is at the least.

\section{Acknowledgments}

This study is granted and supported by Natural Science Foundation of China, the Ministry of Education of China, Shanghai Municipal Education Commission, Shanghai Science and Technology Commission, and Shanghai Maritime University (Grant number: 70541009; 11YJA630067; S30601; ZF1209; 11510501800; 20110020).

\section{References}

Buhaug et al. (2009). Second IMO Greenhouse Gas Study. London: International Maritie Organization, 79-82. 
Cariou, P. (2011). Is Slow Steaming a Sustainable Means of Reducing $\mathrm{CO}_{2}$ Emissions from Container Shipping. Transportation Research Part D, 16, 260-264. http://dx.doi.org/10.1016/j.trd.2010.12.005

Corbett, J.J., Wang, H., \& Winebrake, J.J. (2009). The Effectiveness and Costs of Speed Reduction on Emissions from International Shipping. Transportation Research Part D: Transport and Environment, 8(12), 593-598. http://dx.doi.org/10.1016/j.trd.2009.08.005

Psaraftis, H., \& Kontovas, C. (2010). Balancing the Economic and Environmental Performance of Maritime Transportation. Transportation Research Part D, 15, 458-462. http://dx.doi.org/10.1016/j.trd.2010.05.001

Zhang, S., Zhang, S., \& Li, Y. (2008). Overview of Measures for Reduction of GHG Emission from International Shipping. China Maritime Safety, 5, 60-64.

Zhao, G. (2006). International shipping management. Press of Dalian Maritime University, 9394.

Journal of Industrial Engineering and Management, 2013 (www.jiem.org)

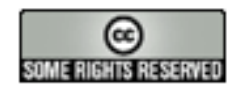

El artículo está con Reconocimiento-NoComercial 3.0 de Creative Commons. Puede copiarlo, distribuirlo y comunicarlo públicamente siempre que cite a su autor y a Intangible Capital. No lo utilice para fines comerciales. La licencia completa se puede consultar en http://creativecommons.org/licenses/by-nc/3.0/es/ 